\section{Discussion}

The original $15 \mathrm{EU}$ states have some of the strongest publication records, and their ranking individually within that group changes depending on the indicator used. For example, raw numbers favour the United Kingdom, Germany, France, and Italy (the four most populous countries), whereas adjusted indicators favour the Scandinavian countries and the Netherlands. The research productivity of many of the original member countries, adjusted for population size or for funds devoted to research and development, far exceeds the productivity of the US, but productivity for the EU as a whole, adjusted for population, is only two thirds that for the US. Furthermore, some of the 10 newest EU states (Slovenia, Hungary, Estonia, and the Czech Republic) have higher indicators than the lowest ranking countries of the original $15 \mathrm{EU}$ states. The four candidate countries, in general, have lower indicators than the 10 newest EU states, with the exception of publications per billions of US dollars devoted to research and development, where they rank higher.

The negative geographical gradient from north to south and west to east, evident by other indicators, is also present in the biomedical research within the European Union. ${ }^{6}$ Although the US leads the biomedical research race by most indicators, the original group of $15 \mathrm{EU}$ states as a whole was not far behind. Moreover, US based journals are more heavily represented than European journals in the Institute for Scientific Information's databases, ${ }^{7}$ therefore affording the US an advantage not adjusted for in our comparison. However, the accession of the 10 newest EU states resulted in a substantial dilution of research indicators and a considerable increase in the publication gap in relation to the US, which is due to worsen with the planned accession of candidate countries, excluding the indicator adjusted for funds devoted to research and development.

Given the importance of biomedical research in economic development, we urge the EU governing bodies, along with the scientific community, to further strengthen research networks of excellence in the EU and continue to increase funding opportunities in biomedical research (as has happened with the sixth

\section{What is already known on this topic}

The European Union and the United States are the leading powers in biomedical research and publications, although the US is ahead of the EU in most scientific disciplines

The EU has been gradually closing this gap, but the union's future expansion might widen the gap again in favour of the US

\section{What this study adds}

Research productivity for the $\mathrm{EU}$ as a whole, adjusted for population, is only two thirds that for the US and may dip further in relation to the US once the four candidate countries join the union

framework programme in support of research in the $\mathrm{EU}$ and the candidate countries, as well as in some eastern European countries not in the EU). ${ }^{8}$ Furthermore, the newest EU members and the candidate countries need particular attention to increase their research productivity and improve their indicators, thus raising productivity for the $\mathrm{EU}$ as a whole.

We thank Ioannis A Bliziotis and Evi Papastamataki for their help with data collection and analysis.

Contributors: ESS and MEF designed the study, supervised data collection and analysis, and wrote the report. MEF is the guarantor.

Funding: None.

Competing interests: None declared.

Ethical approval: Not needed.

1 Vergidis PI, Karavasiou AI, Paraschakis K, Bliziotis I, Falagas ME. A bibliometric analysis of global trends of research productivity in microbiology. Eur J Clin Microbiol Infect Dis 2005;24:342-6.

2 Rosmarakis ES, Vergidis PI, Soteriades ES, Paraschakis K, Papastamataki PA, Falagas ME. Estimates of global production in cardiovascular diseases research. Int J Cardiol 2005;100:443-9.

3 Stossel TP, Stossel SC. Declining American representation in leading clinical-research journals. N Engl J Med 1990;322:739-42.

EU eliminates citation gap with America. Nature 1997;387:537.

EU eliminates citation gap with America. Nature 1997;387:537.
The World Bank. World development indicators 2002. CD Rom. 2004.

6 Manfrass K. Europe: south-north or east-west migration? Int Migr Rev Manfrass K. Europe: south-north or east-west migration? Int Migr Rev 1992;26:388-400.

Zetterstrom R. Bibliometric data: a disaster for many non-American biomedical journals. Acta Paediatr 2002;91:1020-4.

8 Auger JM, Lymberis A. Current and future R\&D activities of the EC-IST programme in eHealth. Stud Health Technol Inform 2004;108:81-7.

\title{
Commentary: Bridging the gaps in biomedical research
}

\author{
Stella Fatovic-Ferencic
}

Croatian Academy of Arts and Science Department for the History and

Philosophy of

Science, Division for

the History of

Medicine, Zagreb,

Croatia

Stella

Fatovic-Ferencic

professor

stella@hazu.hr
Soteriades and Falagas ${ }^{1}$ and Burazeri and colleagues ${ }^{2}$ explored the distribution of quality research on either side of the Atlantic and in southeastern Europe. The well known North-South and West-East divides re-emerged. The authors emphasise the negative influence that the accession of the new member states will have on the total scientific output of the European Union, as well as the greater productivity of US authors that already exists.

Science is the environment of different traditions that are unequally distributed among countries and cultures. Historically, its development is deeply rooted in social and cultural processes and often imbued with aspects of power, authority, and control. Totalitarian dictatorships provided us with a variety of examples, but democracies provided some examples as well. Reflecting on how science was transformed through the mediation of unequal power relations is necessary if we are to attempt to rethink strategies for bridging the existing gaps in biomedical research.

Political and economic experiences are a structural part of modern knowledge. We can hardly discuss knowledge or science without considering the political and economic dimensions of their emergence and use. The West-East and North-South gradients in scientific output are surely related to availability of resources, 
established research centres, familiarity with today's lingua franca (English), and scientific and individual traditions. Biotechnology requires money, which was and remains scarce in transitional countries.

The succession of Roman, Byzantine, French, Austro-Hungarian, and Russian cultural traditions in these countries also had negative consequences, particularly on free development and autonomy of education and science. In addition, communism, which combined a scientific view of the world with monolithic coercive power and strict social control, helped create intolerance to scientific creativity. Meanwhile, the dominance of the science-centred West, particularly after the second world war, stimulated cultural change of profound importance. Scientists who emerged in the United States, Canada, and the United Kingdom were regarded as having a public mission and a legitimate claim to political influence. ${ }^{3}$ They participated in creating "knowledge societies," in which expert-run systems are incorporated into all parts of social life.

To address this North-South, West-East divide, I suggest that both sides work hard: teach English to improve scientific communication, explore funding possibilities that the European Union might provide, provide computer technology, encourage young people (who have proved their interest in science) to

\section{To bridge the gaps in scientific output}

Improve sharing of scientific programmes

Enhance communication and run multinational projects

Encourage academic freedom and autonomy of science

Promote scientific communities worldwide in order to build creative, potent knowledge cultures that will bridge geographical and political boundaries

apply for scholarships and gain experience in the developed world. It worked for Western Europe after the second world war, and it should work for transitional countries today. The role of power in the social structure of science clearly has had an effect on its distribution worldwide. Perhaps the time has come not only to declare obvious research inequalities but to rethink our strategies and use power to bridge the gaps.

1 Soteriades ES, Falagas ME. Comparison of amount of biomedical research originating from the European Union and the United States. BMJ 2005;331:192-5

2 Burazeri G, Civljak M, Ilakovac V, Jankovic S, Kovacevic TM, Nedera O, et al. Survey of attitudes and knowledge about science in medical students in southeast Europe. BMJ 2005;331:192-9.

3 Ben-David J. Scientific growth. Essays on the social organization and the ethos of science. Berkeley, CA: University of California Press, 1991: 510-45.

\section{Survey of attitudes and knowledge about science in medical students in southeast Europe}

\section{Genc Burazeri, Marta Čivljak, Vesna Ilakovac, Slobodan Janković, Tanja Majica-Kovačević, Olesea Nedera, Enver Roshi, Valeriu Sava, Vladimir Šimunović, Ana Marušić, Matko Marušić}

For the countries of southeast Europe, joining the European Union would mean a fundamental reassessment of beliefs, attitudes, values, and structures developed during 50 years of communist regimes. ${ }^{1}$ This would include their healthcare systems and the training of their healthcare professionals. Medical schools in southeast Europe will need to restructure medical curriculums within the unified Europe. ${ }^{2}$ Medical students will have to learn modern evidence based medicine, ${ }^{3}$ for which they have not been prepared, mainly because of weak research output of their countries and inadequate education in research methods. ${ }^{4}$ To assess medical students' knowledge about research methods and communication and their attitudes towards research in medicine we used a specially constructed and validated questionnaire $^{5}$ in medical schools in five post-communist countries.

\section{Participants, methods, and results}

In total 4307 students (66\% response rate) answered a voluntary and anonymous questionnaire. The questionnaire contained a 45 item Likert-type scale developed to measure attitudes towards science, grouped in three subscales, and an eight item knowledge test of principles of scientific research. ${ }^{5}$ The study was performed simultaneously at all schools, and students in all six years of their studies who were present at lectures could take part in the study.

Students generally had poor knowledge of research methods (mean of three correct answers out of a maximum of eight), with Albanian students scoring significantly lower than all other students (table). Students from Chisinau in Moldova and Mostar in Bosnia and Herzegovina performed significantly better than other students but showed opposite trends according to year of study. In Chisinau the knowledge score increased from 36\% (95\% confidence interval $34 \%$ to $38 \%$ ) of correct answers for first year students to $45 \%$ ( $43 \%$ to $47 \%$ ) for sixth year students, whereas students at Mostar had the best knowledge scores in the first year $(73 \%, 70 \%$ to $76 \%$, correct answers) but only $22 \%$ (14\% to $32 \%)$ at the end of medical studies.

Despite poor knowledge scores, students had generally positive attitudes towards science, the highest

Characteristics of the medical schools and countries in the survey can be found on bmj.com
Public Health,

Faculty of Medicine,

Tirana University,

Tirana, Albania

Genc Burazeri

lecturer of

epidemiology and

research methods

Enver Roshi

lecturer of

epidemiology and

research methods

Department of

Medical Sociology

and Health

Economics, Andrija

Stampar School of

Public Health,

Zagreb University

School of Medicine,

Zagreb, Croatia

Marta Čivljak

research fellow

Department of

Medical Statistics

and Medical

Informatics, School

of Medicine, Josip

Juraj Strossmayer

University of Osijek,

Osijek, Croatia

Vesna Ilakovac

lecturer in medical

informatics

continued over

BMJ 2005;331:195-6 